\title{
System for open-chest, multidirectional electrical defibrillation
}

\author{
Marcelo Almeida Viana*, Rosana Almada Bassani, Orlando Petrucci, Denilson Antônio Marques, \\ José Wilson Magalhães Bassani
}

\begin{abstract}
Introduction: Cardiomyocytes are more sensitive to stimulatory electrical fields when the latter are applied longitudinally to the cell major axis. In the whole heart, cells have different spatial orientations, which may limit the effectiveness of conventional electrical defibrillation (i.e., shock delivery in a single direction). This article describes the constructive aspects of a portable system for rapidly-switching, multidirectional stimulus delivery, composed of an electrical defibrillator and multielectrode-bearing paddles for direct cardiac defibrillation. Methods: The defibrillator delivers monophasic, truncated monoexponential waveforms with energy up to $7.3 \mathrm{~J}$. Upon selection of the defibrillation modality (unidirectional or multidirectional), shock delivery is triggered through 1 or 3 outputs. In the latter case, triggering is sequentially switched to the outputs, without interval or temporal overlap. Each paddle contains 3 electrodes that define shock pathways spaced by $60^{\circ}$. The system was tested in vivo for reversal of experimentally-induced ventricular fibrillation in healthy swine, using 30- and 20-ms long shocks ( $\mathrm{N}=4$ in each group). Results: The defibrillator delivers identical stimulus waveforms through all outputs in both stimulation modalities. In all animals, successful defibrillation required lower shock energy when 20 ms-long stimuli were applied in 3 directions, compared to a single direction. However, performance was poorer with multidirectional defibrillation for $30 \mathrm{~ms}-$ long shocks. Conclusion: The delivery of identical shock waveforms allowed confirmation that multidirectional defibrillation can promote restoration of sinus rhythm with lower shock energy, which may reduce myocardial electrical damage during defibrillation. Nevertheless, increase in shock duration greatly impairs the effectiveness of this defibrillation modality.
\end{abstract}

Keywords: Cardiac arrhythmia, Ventricular fibrillation, Cardiac defibrillator, Shock duration.

\section{Introduction}

Cardiac arrest caused by ventricular fibrillation (VF) is a leading cause of sudden death, which is estimated to account for $15-20 \%$ of all deaths (Hayashi et al., 2015). The chance of survival drops by $\sim 5 \%$ for every minute of untreated VF (Larsen et al., 1993). Electrical defibrillation, which consists of the application of a brief, high-intensity electrical shock to the heart, is the most effective therapy in the early phase of VF (Koster et al., 2006; Patil et al., 2015).

Nonetheless, exposure to high-intensity electrical fields may cause harmful effects on the heart muscle, attributed to electrical cell membrane damage and consequent $\mathrm{Ca}^{2+}$ overload (Fedorov et al., 2008; Krauthamer and Jones, 1997; Oliveira et al., 2008; Yabe et al., 1990). Although the minimum electrical field required for successful defibrillation is estimated as 3-9 V/cm (Malmivuo and Plonsey, 1995), during defibrillation the field may reach $\sim 100 \mathrm{~V} / \mathrm{cm}$ near the electrodes (Kroll and Swerdlow, 2007; Yabe et al., 1990), which is higher than the threshold values for membrane electroporation $(>25 \mathrm{~V} / \mathrm{cm}$, Cheek and
Fast, 2004) and cell death (>50 V/cm; Goulart et al., 2012; Oliveira et al., 2008).

Optimizing the direction of stimulation might decrease the field intensity required for effective stimulation, since, for field application parallel to the cell major axis, the threshold intensity is only $50 \%$ of that when the field is applied in the transversal direction (Bassani et al., 2006; Oliveira et al., 2008). A problem of the practical application of this approach to defibrillation is that myocytes are disposed in several directions in the whole heart (Smerup et al., 2009). Nevertheless, using randomly-oriented isolated ventricular myocytes as an experimental model for heterogeneous cell spatial orientation, Fonseca et al. (2013) showed that rapidly switching stimuli among 3 directions was able to more than double the percentage of cells excited by near-threshold stimulus amplitude.

The effectiveness of the in vivo multidirectional stimulation for defibrillation has been tested, with the observation of reduction in the shock strength requirement for successful defibrillation when shocks are applied in more than one direction (Chang et al., 
1986; Jones et al., 1988; Kerber et al., 1994; PaganCarlo et al., 1998; Zheng et al., 2002). However, in these studies, different defibrillators were used for shock delivery through different pathways. This may impair the comparison of the effectiveness of unidirectional and multidirectional defibrillation because the applied peak voltage and current for a given level of shock energy may markedly vary among defibrillators. Conventional defibrillators deliver shocks via a single pair of electrodes, thus in a single direction, and, to our knowledge, defibrillators with multiple outputs are not commercially available, even for experimental purposes.

In a recent study, we reported improved in vivo defibrillation by applying stimuli through 3 pathways using a single defibrillator for both unidirectional and multidirectional stimulation (Viana et al., 2014). In the present article, we describe, from the constructive point of view, the system used in the previous study, composed of an electrical defibrillator and electrode-bearing paddles for rapid shock delivery on the epicardial surface in up to 3 directions, with a special focus on the influence of shock duration on the effectiveness of defibrillation.

\section{Methods}

\section{Instrumentation}

\section{The multidirectional defibrillator}

The present instrument, developed at the Center for Biomedical Engineering of the University of Campinas (CEB/UNICAMP), was based on the combination of a switching circuit that allows the output to be changed among different pairs of electrodes (Fonseca et al.,
2013), and a capacitive pulse generator that delivers monophasic, truncated exponential voltage pulses (American National Standards Institute..., 1996; Associação Brasileira de Normas Técnicas..., 2005). In its present version, the instrument can deliver sequential shocks up to 3 outputs (pairs of electrodes).

The block diagram of the multidirectional defibrillator is shown in Figure 1. A rechargeable sealed lead-acid battery (UP-645, Unipower, Extrema, MG, Brazil; $6 \mathrm{~V})$ powers the switched-mode power supply (SMPS) circuit (Figure 2a), which operates in the flyback mode. This circuit contains an adjustable switch regulator (LM2577-ADJ, National Semiconductor Co., Santa Clara, CA, USA) that switches the electrical current at high frequency $(52 \mathrm{kHz})$ to a step-up voltage transformer (TR 70415, Ralp Industrial, Alvorada, RS, Brazil; 1:10), as to stabilize the DC output voltage that charges three $100 \mu \mathrm{F}$ electrolytic capacitors, one for each output. The desired charging voltage level (up to $382 \mathrm{~V}$, corresponding to a maximum of $7.3 \mathrm{~J}$ shock energy) can be adjusted by means of a rotary linear potentiometer $(100 \mathrm{k} \Omega)$ on the front panel of the equipment. The relationship between the time required for fully charging the capacitors and the shock energy level is shown in Figure 2b, where it can be seen that capacitor charging can take as long as $1 \mathrm{~min}$ for the maximum shock energy available.

The SMPS circuit energizes the microcontroller-based control circuit (PIC16F818, Microchip Technology, Inc., Chandler, AZ, USA) and the liquid crystal display (LCD-016M002B, Vishay Intertechnol., Shelton, CT, USA) on the control panel via a linear low dropout voltage regulator (LM2940CT-5.0, National Semiconductor Co., Santa Clara, CA, USA; 5 V).

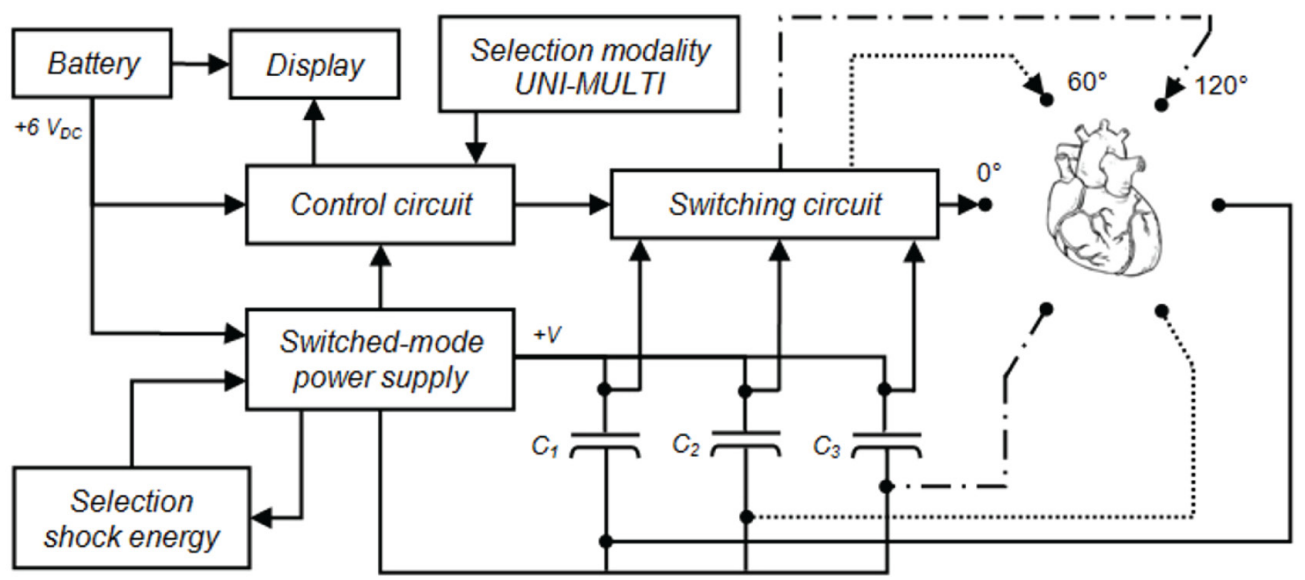

Figure 1. Summarized block diagram of the multidirectional defibrillator. The battery powers the display, control circuit and the switchedmode power supply (which provides controlled voltage to charge the capacitors $C_{1}-C_{3}$ ). The switching circuit controls shock delivery through one or more of the defibrillator outputs, connected pairs of electrodes positioned in different directions. The defibrillation shock energy level and the modality of shock delivery (unidirectional, UNI, or multidirectional, MULTI) can be selected on the panel of the instrument. More detailed versions of specific circuits are shown in Figures 2, 4 and 5. 

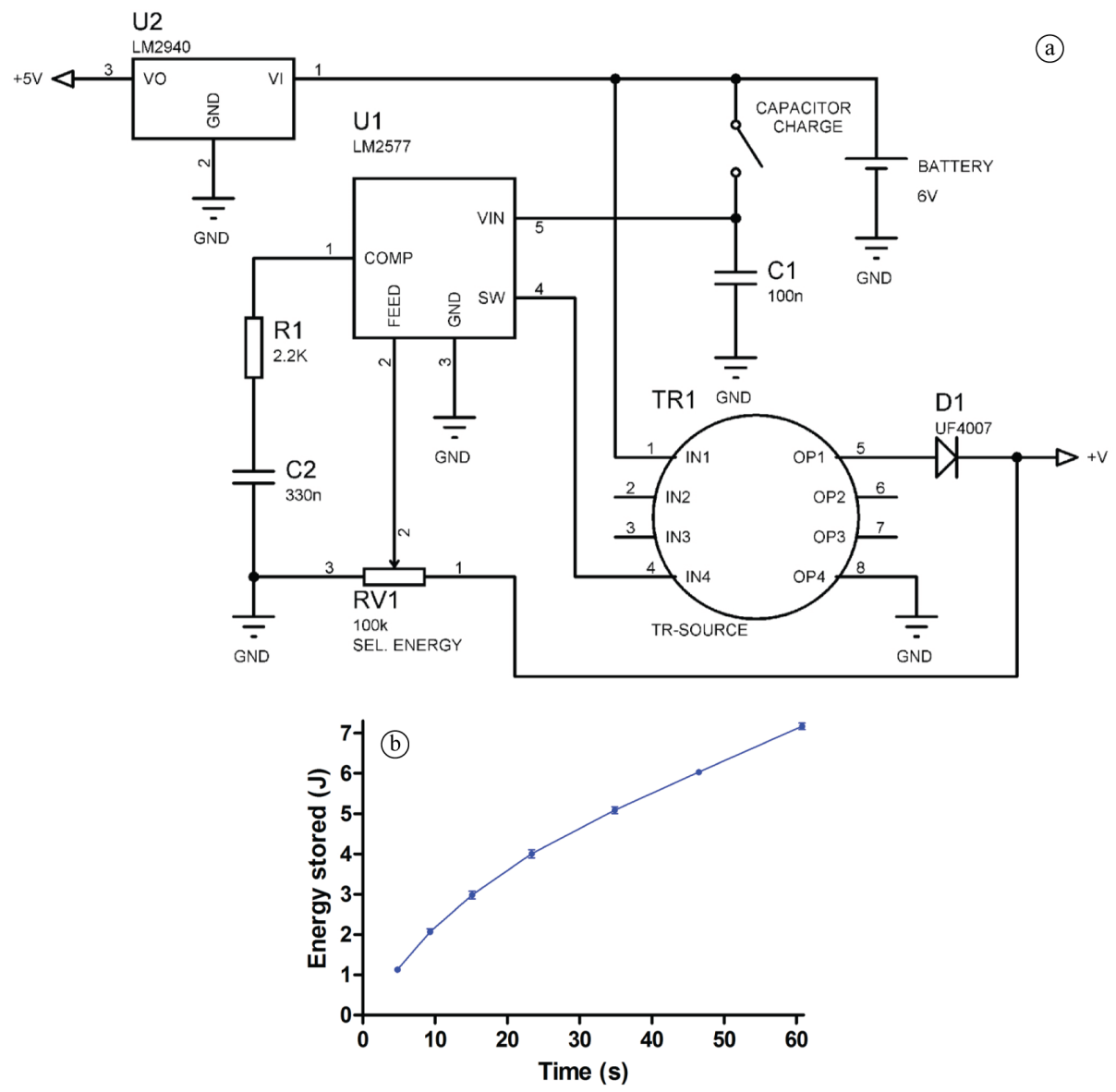

Figure 2. (a) Switched-mode power supply circuit; (b) Time required for charging the three $100 \mu \mathrm{F}$ electrolytic capacitors by the SMPS circuit, depending on the preset shock energy level. Points are mean \pm standard error of the mean $(\mathrm{N}=10)$.

The modality of shock delivery (unidirectional or multidirectional, i.e., through 1 or 3 electrodes pairs, respectively) can also be preset on the front panel (Figure 3). These settings configure the operating mode control circuit (Figure 4a), which commands the output switching. The microcontroller functions were programmed in assembly language, and the program was written and loaded in the microcontroller using the MPLAB ${ }^{\circledR}$ IDE recorder software (Microchip Technol. Inc., Chandler, AZ, USA).

When shock delivery is triggered, a command pulse chopped at $1 \mathrm{kHz}$ is generated by the microcontroller, as an interval-modulated train of rectangular voltage pulses. The train duration (set at either 20 or $30 \mathrm{~ms}$ ) defines the duration of the each defibrillatory shock. If the unidirectional delivery modality is selected (Figure $4 \mathrm{~b}$ ), a single pulse train voltage (S60) is generated, in this case to trigger stimulus delivery through the central electrodes in the paddles (see next). If the multidirectional modality is set, triggering pulse trains are generated sequentially (S0, S60 and S120,
Figure 4c), without interval or temporal overlap, to trigger successive shock delivery though each of the 3 pairs of electrodes, thus allowing switching the defibrillator outputs. Current backflow from the fully charged capacitors is prevented by six blocking diodes (6A10, Rectron Semiconductor Inc., Chino, CA, USA), which ensures the establishment of a floating potential configuration. Pulse transformers (TP-1:1/4T, Thornton, Vinhedo, SP, Brazil) were used with chopped pulses to ensure that switching was triggered, and to isolate the high-voltage switching circuit from the low-voltage control circuit. The discharge switching circuit (one for each output, Figure 5a) was implemented by using bidirectional thyristors (triodes) for alternating current (TRIAC 226M, Power Innov., Inc., Lindon, UT, USA) sufficiently fast for delivery of up to 3 shocks within $60 \mathrm{~ms}$ (Figure $5 \mathrm{~b}$, c), i.e., in a shorter period than the duration of the absolute refractory period of action potential in the swine ventricle (Roscher et al., 2001). This ensures that a 


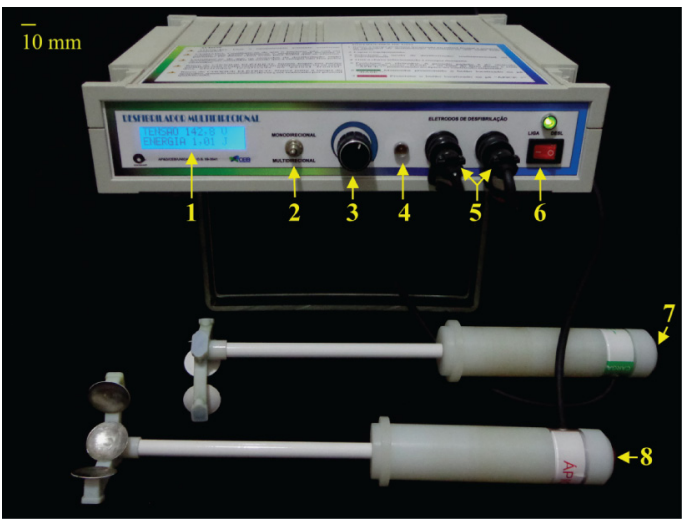

Figure 3. The multidirectional defibrillator and the paddles. From the left to the right in the instrument's control panel: (1) display that shows the charged voltage and energy level; (2) switch for selection of shock delivery modality; (3) rotary potentiometer for adjusting shock energy; (4) LED that indicates stimulus delivery; (5) outputs for connection to the electrode cables; and (6) on/off switch. Each paddle bears 3 electrodes, which allow shock delivery in 3 directions spaced by $60^{\circ}$ (see text for details). Labeled pushbuttons on the top of each handle enable capacitor charging (7) or discharge triggering (8). cardiac myocyte excited by one of the shocks will not be reexcited by the subsequent stimulus.

\section{Internal defibrillation paddles and electrodes}

A pair of defibrillation paddles was designed to contain 3 electrodes each, as to allow direct multidirectional electrical stimulation of the ventricular surface (Figure 3). The paddle handle is a $32 \mathrm{~mm}$ diameter, $140 \mathrm{~mm}$ long, cylindrical nylon tube with labeled pushbuttons on the top, for enabling capacitor voltage charging after the shock energy level is selected (green), and for triggering shock delivery (red). A hollow support shaft in the handle lengthens the paddles, facilitating shock application and minimizing the possibility of contact of the operator with the electrode conductive area. The cables for electrical connection of the defibrillator outputs and the electrodes were inserted into the shaft central cavity. A semicircular electrode support, made of polycarbonate/acrylnitrile-butadiene-styrene by rapid

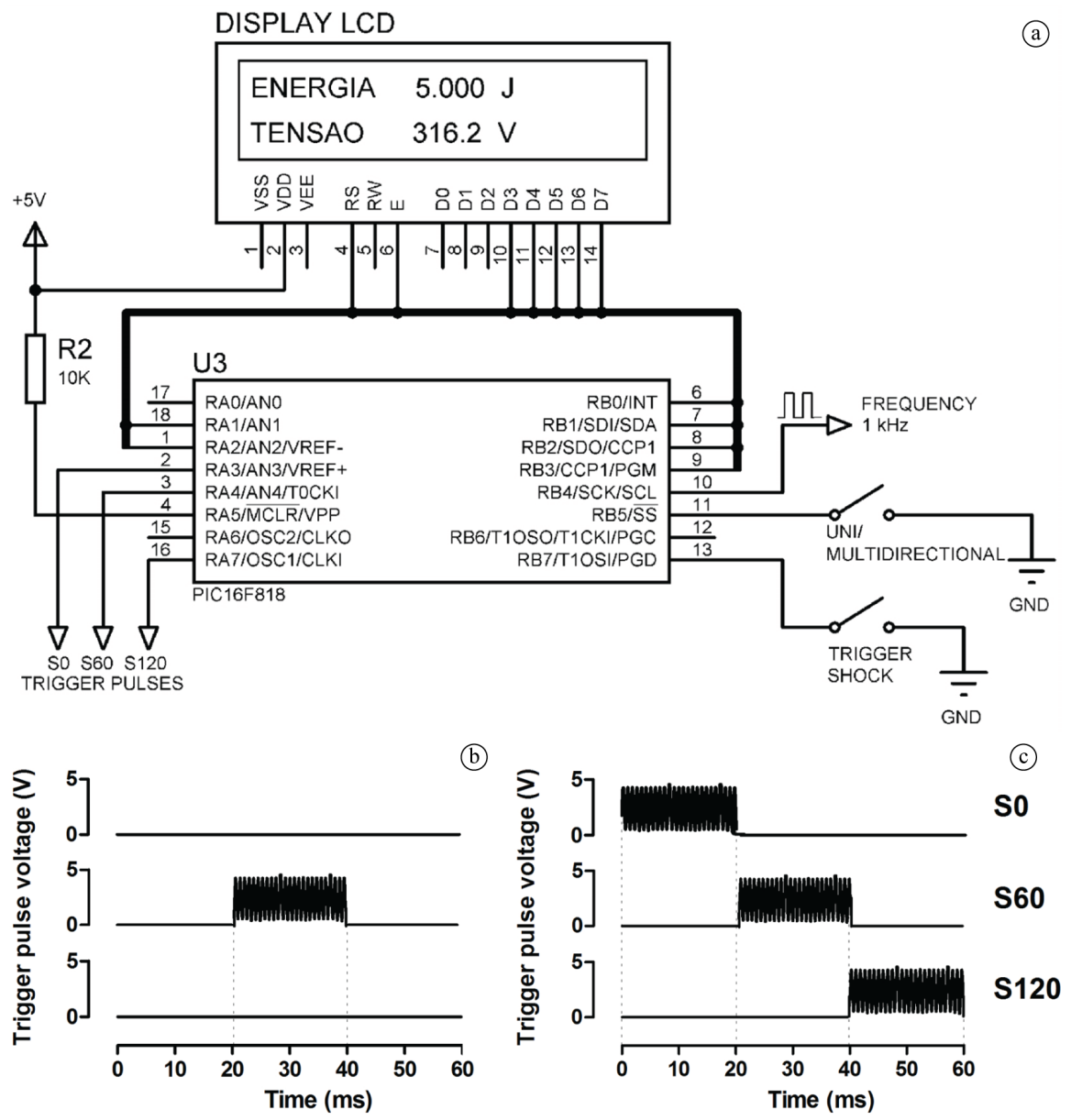

Figure 4. (a) Control circuit; (b) Upon triggering shock delivery, pulse trains are generated by the control circuit to control shock discharge through 1 or 3 outputs (S0, S60 and S120), which are connected to electrodes that define the 3 stimulation directions $\left(0^{\circ}, 60^{\circ}\right.$ and $120^{\circ}$, respectively). In this example, the shock duration was set at $20 \mathrm{~ms}$. 

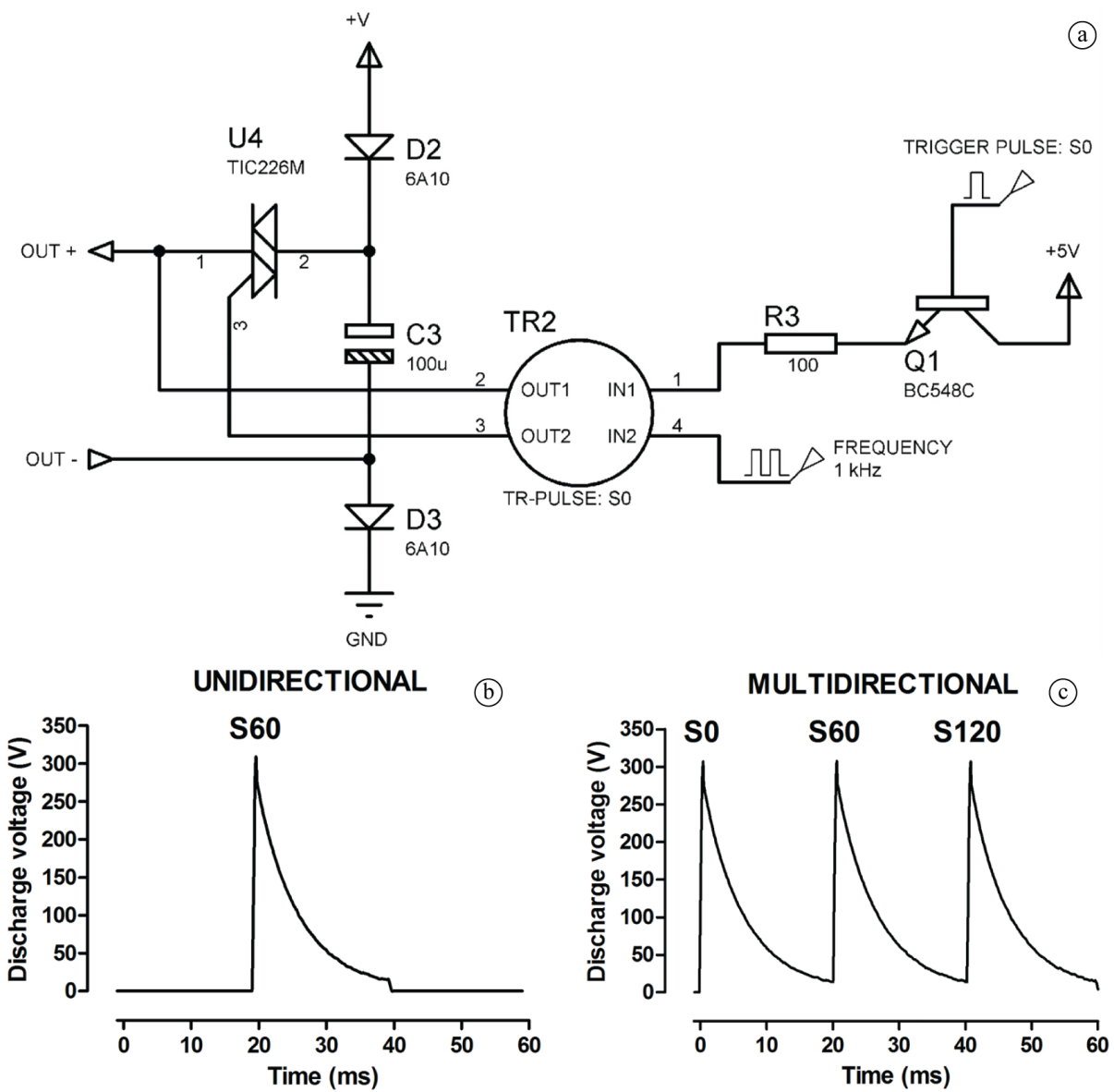

Figure 5. (a) Switching circuit. One of these circuits was used for each output; (b) and (c) Monophasic, truncated exponential shocks (5 $\mathrm{J}$ energy) delivered by the defibrillator in the unidirectional (central electrode, $60^{\circ}$ ) and multidirectional modalities $\left(0^{\circ}, 60^{\circ}\right.$, and $120^{\circ}$ ).

prototyping at the Institute of Biofabrication of the Faculty of Chemical Engineering of the University of Campinas (BIOFABRIS/UNICAMP), was fixed at the inferior extremity of the paddle. The electrodes, shaped as concave discs, were made of polished surgical stainless steel $(25 \mathrm{~mm}$ radius, $1 \mathrm{~mm}$ thickness, $2 \mathrm{~mm}$ depth) and fixed to the polycarbonate support. Lateral electrodes were positioned on both sides at $60^{\circ}$ with respect to the central electrode, as to configure the 3 directions of shock delivery $\left(0^{\circ}, 60^{\circ}\right.$ and $\left.120^{\circ}\right)$. Thus, the electrode support pieces of both paddles encircle the heart in a way that prevents contact between electrodes, which, on the other hand, can make full contact with the ventricular epicardial surface. After electrode fixation, electrostatic paint was applied to the support surface for electrical insulation.

\section{Bench testing of the defibrillator}

In the initial tests, monophasic, truncated exponential waveforms were obtained by the rapid discharge of the capacitors through a $50 \Omega$ resistive test load connected to the electrode output (assuming that cardiac impedance is equivalent to $50 \Omega$; American National Standards Institute..., 1996; Associação Brasileira de Normas Técnicas..., 2005). The output waveform was recorded with a DSO3062A oscilloscope (Agilent Technologies Inc., Santa Clara, CA, USA) for confirmation of the pulse peak voltage, current and duration.

\section{In vivo test of the defibrillator}

These experiments were conducted at the Laboratory of Surgical Techniques of the Nucleus of Medicine and Experimental Surgery, School of Medical Sciences of the University of Campinas (NMCE/FCM/UNICAMP).

Healthy Landrace Large White pigs (female, 8 week-old; $\mathrm{N}=8$ ) of conventional sanitary standard were maintained at the NMCE/FCM/UNICAMP swine vivarium area, receiving filtered water and industrial chow ad libitum. The animal care and experimental protocols were approved by the Committee of Ethics in 
Animal Use of the Institute of Biology of UNICAMP (protocol number 2251-1).

The in vivo preparation was similar to that described by Petrucci et al. (2003) and Viana et al. (2014). Briefly, the animals, sedated with ketamine (10 mg. $\mathrm{kg}^{-1}$, i.m.) and anesthetized with fentanyl hydrochloride and sodium thiopental $\left(12.5 \mu \mathrm{g} . \mathrm{kg}^{-1}\right.$ and $25 \mathrm{mg} \cdot \mathrm{kg}^{-1}$, i.v., respectively), were artificially ventilated via an orotracheal cannula $\left(10 \mathrm{ml} \cdot \mathrm{min}^{-1} \cdot \mathrm{kg}^{-1}\right.$ body weight, $50 \% \mathrm{O}_{2}$ ), under electrocardiographic monitoring.

Experiments lasted no longer than $4 \mathrm{~h}$. Within $15 \mathrm{~s}$ after VF induction by epicardial, low energy DC stimulation (Euler et al., 1999; Viana et al., 2014), either unidirectional or multidirectional defibrillation was attempted. If the arrhythmia could be reversed, a shock of the same modality, but lower energy, was applied 5-15 min later. If the attempt was not successful, VF was terminated using a conventional defibrillator (Cardiomax, Instramed, Porto Alegre, RS, Brazil), and a higher energy shock of the same modality was used in the next trial. Termination of VF was considered to be successful only if sinus rhythm was completely restored without spontaneous arrhythmia recurrence. After a pair of shock energy values (i.e., effective and ineffective at reverting VF) was obtained, the protocol was repeated for the other defibrillation modality. The modalities were alternated until the animals developed cardiovascular instability, spontaneous arrhythmia and/or unresponsiveness to electrical defibrillation, in which case thiopental anesthesia was deepened and intraventricular injection of $3 \mathrm{M} \mathrm{KCl}$ solution was used for euthanasia.

Two groups of animals (each with $\mathrm{N}=4$ ) were defined based on the shock duration, which was 20 or $30 \mathrm{~ms}$. Overall, shock energy varied from 0.3 to $7 \mathrm{~J}$, although the energy range used in each experiment depended on the sensitivity of the heart to electrical defibrillation (i.e., the average effective energy level was lower for more sensitive hearts).

\section{Data Analysis}

Data are presented as means accompanied by the standard error of the mean (SEM).

The relationship between the probability of defibrillation and shock energy was determined by survival analysis (Altman, 1991) from the pairs of shock energy values obtained in succession. A sigmoid function was fitted to the points resulting from the survival analysis $\left(\mathrm{R}^{2}>0.94\right)$ for estimation of the energy value associated with a probability of defibrillation equal to $0.5\left(\mathrm{SE}_{05}\right)$, which was compared between defibrillation modalities in each animal with the $\mathrm{F}$ test. In addition, the defibrillation failure index (DFI), i.e., the ratio of the number of shocks with energy $\geq 6 \mathrm{~J}$ that failed at defibrillation and the total number of applied shocks of this energy level, was determined in each animal for 20 and $30 \mathrm{~ms}$-long shocks, independently of the number of shock directions used for stimulation. The DFI values for the different shock durations were compared with Mann-Whitney test. Statistical significance was considered to occur for $\mathrm{p}<0.05$.

\section{Results}

The defibrillator is portable ( $300 \mathrm{~mm}$ width, $260 \mathrm{~mm}$ depth, $65 \mathrm{~mm}$ height; $2 \mathrm{~kg}$ ) and of simple operation. The paddle design allowed complete contact between the ventricular epicardial and electrode surfaces. The bench tests showed that, for different resistive loads $(9,50,115,229$, and $560 \Omega)$, the pulse waveforms had similar peak voltage for both unidirectional and multidirectional stimulus delivery within the whole energy range, except for the lowest tested resistance $(9 \Omega)$, at which the pulse peak voltage was decreased (Figure 6). As expected, the exponential voltage decay time course was markedly influenced by the resistive load. Nevertheless, except for $9 \Omega$ resistance, for which the stimulus completely decayed in less than $10 \mathrm{~ms}$, stimuli presented similar durations. It is also important to stress that, at a given energy level, identical shock waveforms (peak voltage and time course) were delivered at the 3 pairs of electrodes for multidirectional stimulation, as well as via the pair of central electrodes in the unidirectional modality (Figure 5b, c).

Table 1 shows data of individual experiments using shocks of either 20 or $30 \mathrm{~ms}$ duration, applied in one or three directions. Failure at defibrillation at the high shock energy range was more common for the longer shocks (DFI median values were 0.634 and 0.000 for 30 and $20 \mathrm{~ms}$ duration, respectively; $\mathrm{p}<0.001$, Mann-Whitney test). As it can be seen in Table 1, it was not possible to determine the defibrillation curves for 2 of the 4 animals to which 30 ms-long shocks were applied, because none of attempts with the multidirectional modality was able to reverse the arrhythmia (DFI =1). In contrast, when multidirectional 20 ms-long shocks were used, successful defibrillation was achieved in all cases (DFI $=0)$.

Figure 7 shows the defibrillation curves for conventional (i.e., unidirectional; dashed curve lines and unfilled symbols) and multidirectional defibrillation (i.e., 3 directions of stimulation; solid lines and filled symbols) obtained with 30 (panel A) and 20 ms-long shocks (panel B). For the longer shocks, curves of only 2 animals are presented because, as explained earlier, the remaining 2 swine were unresponsive to 
multidirectional defibrillation. Each color represents the data from a different animal, which is identified by a number in Figure 7 and Table 1. As it can be seen in the figure, sensitivity to shocks was highly variable among the animals. However, it is possible to observe that, in all experiments using 20 ms-long shocks (Figure $7 \mathrm{~b}$ ), the curve obtained with multidirectional defibrillation was shifted to the left with respect to that determined with unidirectional defibrillation in the same animal. Nevertheless, this did not happen when shocks lasted $30 \mathrm{~ms}$ (Figure 7a). Accordingly, the $\mathrm{SE}_{0.5}$ values estimated from the curves (Table 1) were not statistically different between the unidirectional and multidirectional modalities in the few animals that responded to $30 \mathrm{~ms}$-long shocks, whereas the a statistically significant decrease in the $\mathrm{SE}_{0.5}$ values $(p<0.01)$ occurred for the multidirectional modality in
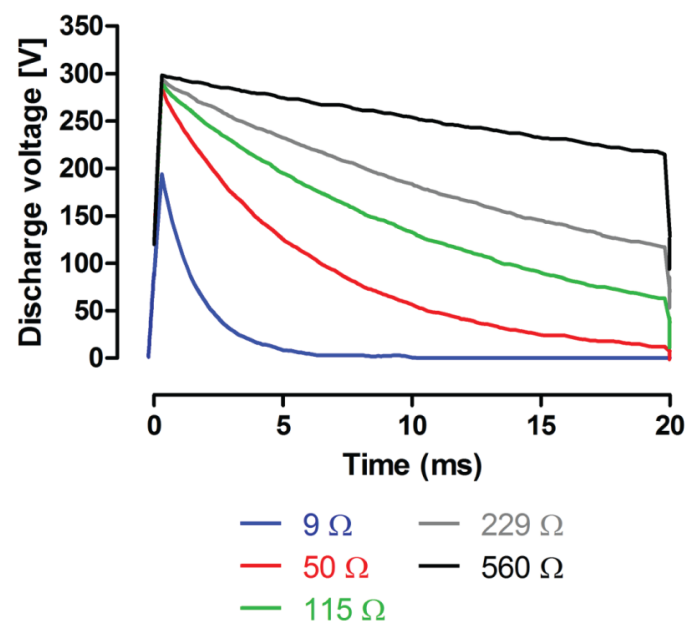

Figure 6. Monophasic truncated exponential waveforms ( $5 \mathrm{~J}$ peak energy) for different resistive test loads $(9,50,115,229,560 \Omega)$. all tested animals receiving shocks with 20 ms duration. These results indicate that, provided that the stimulus was sufficiently short, application of defibrillatory shocks in 3 directions decreased the stimulus energy required for defibrillation, compared to the use of the conventional, unidirectional approach. For further comparison in a larger experimental sample with 20 ms-long shocks, see Viana et al. (2014).

\section{Discussion}

Although several authors have reported greater efficiency of biphasic shocks (Shelton et al., 2011; Tanabe et al., 2012), the defibrillatory monophasic truncated exponential waveform was chosen in present study to better isolate the influence of stimulation direction by removing possible interference of waveformdependent effects on myocardial polarization (Trayanova and Bray, 1997). The delivered discharges in the two defibrillation modalities, and at the 3 defibrillator outputs during multidirectional stimulation, reached the same peak voltage and had similar time course at a given energy level, which eliminated a possible bias caused by variation in the pattern of stimulation in different directions and/or modalities introduced by the use of different equipments for each pathway. The cardiac impedance estimated during application of the defibrillatory pulses $(61 \pm 11 \Omega$; Viana et al., 2014) was in agreement with the standard $50 \Omega$ resistive load assumed for development of cardiac stimulation devices (American National Standards Institute..., 1996; Associação Brasileira de Normas Técnicas..., 2005) and in the project of the present defibrillator.

In this instrument, the duration of the trigger pulse train at the TRIAC gate defines the duration of the

Table 1. Individual data from electrical defibrillation experiments in swine using shocks applied in one or 3 directions. DFI: defibrillation failure index, i.e., the ratio of the number of shocks with energy $\geq 6 \mathrm{~J}$ that failed to restore sinus rhythm and the total number of applied shocks in this energy range. $\mathrm{SE}_{0.5}$ : estimated shock energy associated with a probability of successful defibrillation equal to 0.5 (mean \pm standard error), obtained from the defibrillation curves shown in Figure 7. The number of degrees of freedom of the non-linear regression is shown in parentheses. The $\mathrm{p}$ values obtained with the $\mathrm{F}$ test for comparison of the $\mathrm{SE}_{0.5}$ values between the defibrillation modalities are also shown. $\mathrm{n} / \mathrm{d}$ : not determined.

\begin{tabular}{|c|c|c|c|c|c|}
\hline \multirow{2}{*}{ Subject } & \multicolumn{2}{|c|}{1 Direction } & \multicolumn{2}{|c|}{3 Directions } & \multirow{2}{*}{$\mathbf{p}$} \\
\hline & DFI & $\mathrm{SE}_{0.5}(J)$ & DFI & $\mathrm{SE}_{0.5}(\mathrm{~J})$ & \\
\hline \multicolumn{6}{|c|}{30 ms shock duration } \\
\hline Subject 1 & 0.143 & $2.58 \pm 0.25(3)$ & 0.100 & $2.28 \pm 0.13$ & 0.308 \\
\hline Subject 2 & 0.714 & $\mathrm{n} / \mathrm{d}$ & 1.000 & $\mathrm{n} / \mathrm{d}$ & - \\
\hline Subject 3 & 0.500 & $\mathrm{n} / \mathrm{d}$ & 1.000 & $\mathrm{n} / \mathrm{d}$ & - \\
\hline Subject 4 & 0.555 & $4.83 \pm 0.12(3)$ & 0.461 & $5.11 \pm 0.11(4)$ & 0.226 \\
\hline \multicolumn{6}{|c|}{20 ms shock duration } \\
\hline Subject 5 & 0.000 & $4.11 \pm 0.06(3)$ & 0.000 & $3.57 \pm 0.08$ & $<0.002$ \\
\hline Subject 6 & 0.500 & $5.69 \pm 0.10(3)$ & 0.000 & $4.44 \pm 0.23(3)$ & $<0.004$ \\
\hline Subject 7 & 0.000 & $2.91 \pm 0.04(14)$ & 0.000 & $1.20 \pm 0.02(15)$ & $<0.001$ \\
\hline Subject 8 & 0.000 & $3.81 \pm 0.05(9)$ & 0.000 & $2.98 \pm 0.01(9)$ & $<0.001$ \\
\hline
\end{tabular}



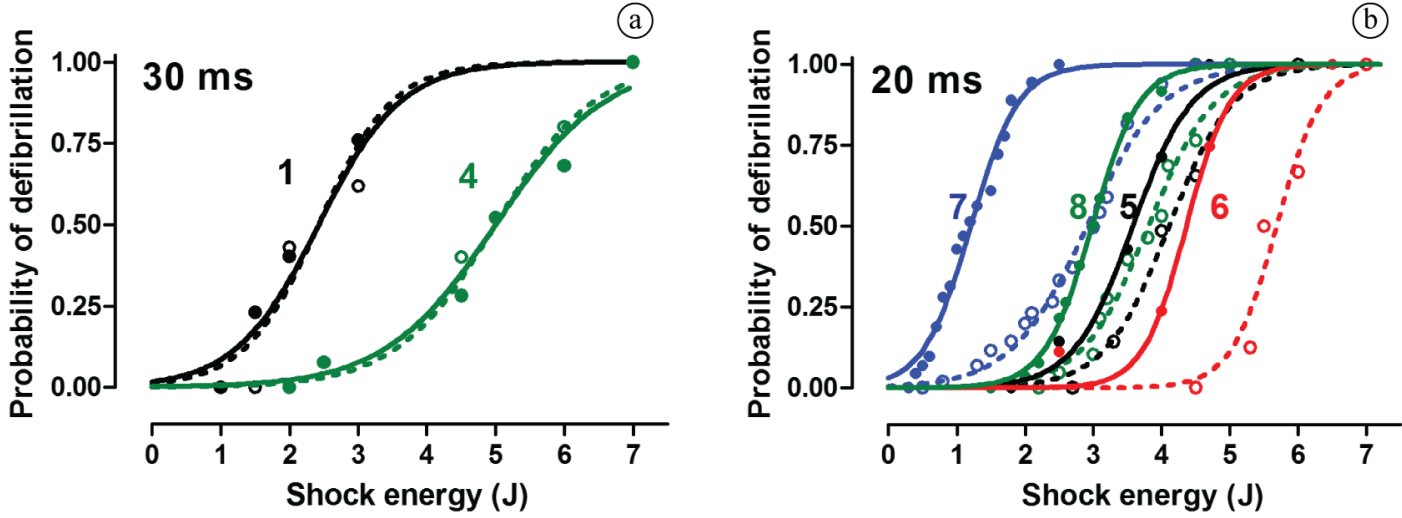

Figure 7. Probability of successful defibrillation as a function of the shock energy estimated from in vivo experiments in swine. Shocks with 30 (panel a) and $20 \mathrm{~ms}$ duration (panel b) were applied in one (dashed curve lines, unfilled symbols) or three directions (solid curve lines, filled symbols). Curves from different animals are identifiable by the colors and the subject numbers, which are the same as in Table 1 .

defibrillatory shock. This electronic type of switch was chosen to avoid prolonging of the total discharge duration, which is observed when relays are used for switching among outputs (Fonseca et al., 2013). The results of the bench and in vivo tests showed that this option resulted in reproducible discharge duration, in agreement with the preset value.

The present study shows that the superior effectiveness of multidirectional defibrillation over the conventional approach is highly dependent on the duration of the defibrillatory pulse. For 30 ms-long stimuli, multidirectional stimulation generally presented a poorer performance than unidirectional defibrillation, as it completely failed at restoring sinus rhythm in half of the tested subjects, even at high shock energy levels. Moreover, in the animals that responded to this modality, defibrillation efficiency (evaluated by the $\mathrm{SE}_{05}$ values) was not statistically different from that of the conventional, unidirectional stimulation. However, the sole decrease of shock duration to $20 \mathrm{~ms}$ not only did enable hearts to respond to multidirectional stimulation, but also revealed the greater efficiency of this defibrillation modality.

Even though the time elapsed for delivery of 3 pulses with $30 \mathrm{~ms}$ duration would be shorter that the reported action potential duration recorded in vitro in swine ventricle at physiological temperatures $(>100 \mathrm{~ms}$; Roscher et al., 2001), it is possible that the in vivo conditions, such as transient myocardial ischemia and increased catecholamine release, resulting from the interruption of cardiac pumping during VF, may have resulted in action potential shortening (Christé et al., 2006; Hoeker et al., 2014). In this case, it is likely that defibrillatory pulses would reach some cells during the relative refractory period (vulnerable period), which would favor arrhythmia reinitiation (Corbisiero et al., 1999), thus masking or even reverting the beneficial effect of multidirectional defibrillation. These observations point out the importance of using short shocks for efficient multidirectional defibrillation.

Despite the choice of $100 \mu \mathrm{F}$ electrolytic capacitors, aimed at minimizing potential damaging effects of the application of high peak voltage and current to the myocardium, the time for attainment of the maximal capacitor charge exceeded the recommended period of 15 s (American National Standards Institute..., 1996; Associação Brasileira de Normas Técnicas..., 2005). In our experimental setup, this has not posed a problem because, in the case of defibrillation failure with the developed instrument, a conventional defibrillator was ready for use. Nevertheless, this limitation needs to be addressed during the development of a prototype for clinical application. Additionally, because 3 electrodes must be accommodated in each paddle support, it was necessary to reduce the contact area of each electrode to less than the minimal area recommended for pediatric internal use (American National Standards Institute..., 1996; Associação Brasileira de Normas Técnicas..., 2005), as to keep them sufficiently apart as to avoid their contact, but still close enough to allow them to fully contact the epicardium,. Again, redesigning the electrode disposition in the paddles is necessary prior to their use in humans. Nevertheless, in the experimental scenario, the smaller contact area did not result in macroscopic changes indicative of burn or other kind of damage in the ventricular epicardium after repeated shock delivery (up to 36 shocks).

It is known that electric fields applied to the heart may produce excitatory or deleterious effects, depending on the intensity. The sensitivity of cardiac cells to both kinds of effect markedly depends on the direction of the field application with respect to the cell or fiber bundle major axis: lower field intensities are required 
to produce both excitation and cell injury when the field direction is parallel to the major axis. This seems to be due to the direction-dependent ability of the field to cause a variation in transmembrane electrical potential sufficient for attainment of the excitation threshold or massive electroporation (Bassani et al., 2006; Goulart et al., 2012; Knisley and Baynham, 1997; Oliveira et al., 2008;). As in the whole heart the muscle fibers are arranged in different directions (Smerup et al., 2009), a shock applied between a pair of electrodes in a given orientation will have different impact on cells with different spatial orientations. Thus, multidirectional stimulation should be able to promote electrical recruitment of cells that might remain unexcited by unidirectional stimulation, thus allowing effective stimulation with lower and safer field intensities. This proposal was confirmed for both near-excitation threshold and high-intensity field stimulation of isolated cardiac myocytes (Fonseca et al., 2013) and of the whole heart in vivo (Viana et al., 2014; present study).

In the present configuration, multidirectional defibrillation consisted of the sequential delivery of shocks in 3 directions, in a $60^{\circ}$ angle from each other, which resulted in an average decrease in shock energy of $30 \%$, compared to a single direction, for a probability of defibrillation success of 0.5 . Although other authors have found an even greater reduction of shock energy requirement using more than one stimulation direction (Chang et al., 1986; Jones et al., 1988; Kerber et al., 1994; Pagan-Carlo et al., 1998), one must consider that, in addition to the possible bias introduced by the use of different defibrillators for shock delivery in different pathways, some authors used temporally overlapping multidirectional shocks (Kerber et al., 1994; Pagan-Carlo et al., 1998), which was avoided in our study. Even though temporal superposition should further enhance excitatory recruitment, it should also increase the damaging potential of high-intensity field stimulation, which may result in failure of defibrillation due to arrhythmia reinduction and/or myocardial injury.

Fonseca et al. (2013) identified two mechanisms involved in the enhanced electrical recruitment of cardiac myocytes during rapidly-switching, sequential application of electrical field in different directions. One of them is direction-dependent, probably due to the induction of threshold depolarization in a greater number of cells, as explained earlier. The other mechanism is time-dependent, and probably involves temporal summation of the depolarization responses evoked by the stimuli delivered in rapid succession, as excitatory recruitment was facilitated also during unidirectional stimulation with pulses applied at very short intervals. The effects of multidirectional and sequential stimulus presentation were additive (Fonseca et al., 2013), which might explain the increased efficiency of our present protocol of rapidly-switching multidirectional defibrillation. It is also important to observe that, despite the large inter-individual variability in sensitivity to defibrillatory shocks (e.g., compare subjects 6 and 7, in which the difference in $\mathrm{SE}_{0.5}$ was at least of $100 \%$, Table 1, Figure 7), multidirectional defibrillation with $20 \mathrm{~ms}$ shocks resulted in a consistent, statistically significant decrease in effective shock energy.

Overall, the developed defibrillation system, unique in its design that allows rapidly-switching multidirectional stimulation with identical waveforms, allowed the confirmation of decrease in shock energy requirement for in vivo direct defibrillation by using shocks sequentially delivered in 3 directions within a short period $(60 \mathrm{~ms})$, in comparison with the conventional approach with a single pair of electrodes. The present data also show that the beneficial effects of multidirectional defibrillation are dependent on shock duration, and abolished with longer stimuli.

\section{Acknowledgements}

We are indebted to Mr. Mauro Martinazo, Mr. Renato S. Moura and Mr. Carlos A. Silva (CEB/UNICAMP), and to Ms. Ana Cristina de Moraes and Mr. William A. Silva (NMCE/FCM/UNICAMP) for technical support to the development of the defibrillator and project documentation, and to the in vivo experiments, respectively. We are also grateful to Mr. André Jardini and Mr. Luis F. Bernardes (BIOFABRIS/UNICAMP) for the contribution to the development of the paddles. This study was supported by the Conselho Nacional de Pesquisa e Desenvolvimento (CNPq), grant $\mathrm{n}^{\mathrm{o}}$ 302996/2011-7 (JWM Bassani) and scholarship $n^{\circ} 135204 / 2008-9$ (MA Viana).

\section{References}

Altman DG. Practical statistics for medical research. London: Chapman and Hall; 1991.

American National Standards Institute. Association for the Advancement of Medical Instrumentation. DF2: cardiac defibrillator devices. New York: ANSI; 1996.

Associação Brasileira de Normas Técnicas. NBR IEC 606012-4: equipamento eletromédico - Parte 2-4: prescrições particulares para segurança de desfibriladores cardíacos. Rio de Janeiro: ABNT; 2005.

Bassani RA, Lima KA, Gomes PAP, Oliveira PX, Bassani JWM. Combining stimulus direction and waveform for optimization of threshold stimulation of isolated ventricular myocytes. Physiological Measurement. 2006; 27(9):851-63. http://dx.doi.org/10.1088/0967-3334/27/9/008. PMid:16868351. 
Chang M, Inoue H, Kallok M, Zipes DP. Double and triple sequential shocks reduce ventricular defibrillation threshold in dogs with and without myocardial infarction. Journal of the American College of Cardiology. 1986; 8(6):1393405. http://dx.doi.org/10.1016/S0735-1097(86)80313-8. PMid:3782643.

Cheek ER, Fast VG. Nonlinear changes of transmembrane potential during electrical shocks: role of membrane electroporation. Circulation Research. 2004; 94(2):208-14. http://dx.doi.org/10.1161/01.RES.0000111526.69133.DE. PMid:14670844.

Christé G, Hadour G, Ovize M, Ferrera R. Brain death does not change epicardial action potentials and their response to ischemia-reperfusion in open-chest pigs. The Journal of Heart and Lung Transplantation. 2006; 25(7):847-53. http:// dx.doi.org/10.1016/j.healun.2006.03.018. PMid:16818129.

Corbisiero R, Kabell G, Cook JR, Fitzgerald TF, Kirchhoffer JB. Effects of adenosine on local stimulus-response latency and induction of atrial fibrillation by premature stimuli. Pacing and Clinical Electrophysiology. 1999; 22(9):137885. http://dx.doi.org/10.1111/j.1540-8159.1999.tb00632.x. PMid:10527020.

Euler DE, Whitman TA, Roberts PR, Kallok MJ. Low voltage direct current delivered through unipolar transvenous leads: an alternate method for the induction of ventricular fibrillation. Pacing and Clinical Electrophysiology. 1999; 22(6):908-14. http://dx.doi.org/10.1111/j.1540-8159.1999. tb06815.x. PMid:10392389.

Fedorov VV, Nikolski VP, Efimov IR. Effect of electroporation on cardiac electrophysiology. Methods in Molecular Biology (Clifton, N.J.). 2008; 423:433-48. http://dx.doi. org/10.1007/978-1-59745-194-9_34. PMid:18370220.

Fonseca ASV, Bassani RA, Oliveira PX, Bassani JWM. Greater cardiac cell excitation efficiency with rapidly switching multidirectional electrical stimulation. IEEE Transactions on Biomedical Engineering. 2013; 60(1):28-34. http:// dx.doi.org/10.1109/TBME.2012.2220766. PMid:23033428.

Goulart JT, Oliveira PX, Bassani JWM, Bassani RA. The influence of cell dimensions on the vulnerability of ventricular myocytes to lethal injury by high-intensity electrical fields. Revista Brasileira de Engenharia Biomédica. 2012; 28(4):337-45. http://dx.doi.org/10.4322/rbeb.2012.040.

Hayashi M, Shimizu W, Albert CM. The spectrum of epidemiology underlying sudden cardiac death. Circulation Research. 2015; 116(12):1887-906. http://dx.doi.org/10.1161/ CIRCRESAHA.116.304521. PMid:26044246.

Hoeker GS, Hood AR, Katra RP, Poelzing S, Pogwizd SM. Sex differences in $\beta$-adrenergic responsiveness of action potentials and intracellular calcium handling in isolated rabbit hearts. PLoS One. 2014; 9(10):e111411. http://dx.doi. org/10.1371/journal.pone.0111411.

Jones DL, Klein JG, Rattes MF, Sohla A, Sharma AD. Internal cardiac defibrillation: single and sequential pulses and a variety of lead orientations. Pacing and Clinical Electrophysiology. 1988; 11(5):583-91. http://dx.doi. org/10.1111/j.1540-8159.1988.tb04554.x. PMid:2456537.
Kerber RE, Spencer KT, Kallok MJ, Birkett C, Smith R, Yoerger D, Kieso RA. Overlapping sequential pulses: a new waveform for transthoracic defibrillation. Circulation. 1994; 89(5):2369-79. http://dx.doi.org/10.1161/01.CIR.89.5.2369. PMid:8181163.

Knisley SB, Baynham TC. Line stimulation parallel to myofibers enhances regional uniformity of transmembrane voltage changes in rabbit hearts. Circulation Research. 1997; 81(2):229-41. http://dx.doi.org/10.1161/01.RES.81.2.229. PMid:9242184.

Koster RW, Walker RG, Van Alem AP. Definition of successful defibrillation. Critical Care Medicine. 2006; 34(12 Suppl):423-6. http://dx.doi.org/10.1097/01.CCM.0000246008.95156.78. PMid:17114971.

Krauthamer V, Jones JL. Calcium dynamics in cultured heart cells exposed to defibrillator-type electric shocks. Life Sciences. 1997; 60(22):1977-85. http://dx.doi.org/10.1016/ S0024-3205(97)00162-8. PMid:9180351.

Kroll MW, Swerdlow CD. Optimizing defibrillation waveforms for ICDs. Journal of Interventional Cardiac Electrophysiology. 2007; 18(3):247-63. http://dx.doi. org/10.1007/s10840-007-9095-z. PMid:17541815.

Larsen MP, Eisenberg MS, Cummins RO, Hallstrom AP. Predicting survival from out-of-hospital cardiac arrest: a graphic model. Annals of Emergency Medicine. 1993; 22(11):1652-8. http://dx.doi.org/10.1016/S01960644(05)81302-2. PMid:8214853.

Malmivuo J, Plonsey R. Bioelectromagnetism: principles and applications of bioelectric and biomagnetic fields. New York: Oxford University Press; 1995.

Oliveira PX, Bassani RA, Bassani JWM. Lethal effect of electric fields on isolated ventricular myocytes. IEEE Transactions on Biomedical Engineering. 2008; 55(11):2635-42. http:// dx.doi.org/10.1109/TBME.2008.2001135. PMid:18990634.

Pagan-Carlo LA, Allan JJ, Spencer KT, Birkett CL, Myers R, Kerber RE. Encircling overlapping multipulse shock waveforms for transthoracic defibrillation. Journal of the American College of Cardiology. 1998; 32(7):2065-71. http:// dx.doi.org/10.1016/S0735-1097(98)00486-0. PMid:9857894.

Patil KD, Halperin HR, Becker LB. Cardiac arrest: resuscitation and reperfusion. Circulation Research. 2015; 116(12):20419. http://dx.doi.org/10.1161/CIRCRESAHA.116.304495. PMid:26044255.

Petrucci O Jr, Oliveira PP, Carmo MR, Vieira RW, Braile DM. Standardization of an isolated pig heart preparation with parabiotic circulation: methodological considerations. Brazilian Journal of Medical and Biological Research. 2003; 36(5):649-59. PMid:12715085.

Roscher R, Arlock P, Sjöberg T, Steen S. Effects of dopamine on porcine myocardial action potentials and contractions at $37^{\circ} \mathrm{C}$ and $32^{\circ} \mathrm{C}$. Acta Anaesthesiologica Scandinavica. 2001; 45(4):421-6. http://dx.doi.org/10.1034/j.13996576.2001.045004421.x. PMid:11300379.

Shelton RJ, Brown BD, Allinson A, Johnson T, Smales C, Jolly S, Cleland JG. A comparison between monophasic and biphasic defibrillation for the cardioversion of persistent atrial fibrillation in patients with and without heart failure. 
International Journal of Cardiology. 2011; 147(3):405-8. http:// dx.doi.org/10.1016/j.ijcard.2009.09.545. PMid:19861229.

Smerup M, Nielsen E, Agger P, Frandsen J, VestergaardPoulsen P, Andersen J, Nyengaard J, Pedersen M, Ringgaard S, Hjortdal V, Lunkenheimer PP, Anderson RH. The threedimensional arrangement of the myocytes aggregated together within the mammalian ventricular myocardium. The Anatomical Record. 2009; 292(1):1-11. http://dx.doi. org/10.1002/ar.20798. PMid:19051244.

Tanabe S, Yasunaga H, Ogawa T, Koike S, Akahane M, Horiguchi H, Hatanaka T, Yokota H, Imamura T. Comparison of outcomes after use of biphasic or monophasic defibrillators among out-of-hospital cardiac arrest patients: a nationwide population-based observational study. Circulation: Cardiovascular Quality and Outcomes. 2012; 5(5):689-96. http://dx.doi.org/10.1161/CIRCOUTCOMES.112.965319. PMid:22967787.

Trayanova N, Bray MA. Membrane refractoriness and excitation induced in cardiac fibers by monophasic and biphasic shocks. Journal of Cardiovascular Electrophysiology. 1997; 8(7):745-57. http://dx.doi.org/10.1111/j.1540-8167.1997. tb00833.x. PMid:9255682.

Viana MA, Bassani RA, Petrucci O, Marques DA, Bassani JW. Rapidly switching multidirectional defibrillation: reversal of ventricular fibrillation with lower energy shocks. The Journal of Thoracic and Cardiovascular Surgery. 2014; 148(6):3213-8. http://dx.doi.org/10.1016/j.jtcvs.2014.07.035. PMid:25173125.

Yabe S, Smith WM, Daubert JP, Wolf PD, Rollins DL, Ideker RE. Conduction disturbances caused by high current density electric fields. Circulation Research. 1990; 66(5):1190-203. http://dx.doi.org/10.1161/01.RES.66.5.1190. PMid:2335021.

Zheng X, Benser ME, Walcott GP, Smith WM, Ideker RE. Reduction of the internal atrial defibrillation threshold with balanced orthogonal sequential shocks. Journal of Cardiovascular Electrophysiology. 2002; 13(9):904-9. http://dx.doi.org/10.1046/j.1540-8167.2002.00904.x. PMid:12380930.

\footnotetext{
Authors

Marcelo Almeida Viana ${ }^{1 *}$, Rosana Almada Bassani ${ }^{2}$, Orlando Petrucci ${ }^{3}$, Denilson Antônio Marques ${ }^{1}$, José Wilson Magalhães Bassani ${ }^{1,2}$

${ }^{1}$ Department of Biomedical Engineering, School of Electrical and Computer Engineering, Universidade Estadual de Campinas - UNICAMP, Av. Albert Einstein, 400, Sala 221, CEP 13083-852, Campinas, SP, Brazil.

${ }^{2}$ Center for Biomedical Engineering, Universidade Estadual de Campinas - UNICAMP, Campinas, SP, Brazil.

${ }^{3}$ Department of Surgery, School of Medical Sciences, Universidade Estadual de Campinas - UNICAMP, Campinas, SP, Brazil.
} 